\title{
A CIDADE E O IDOSO: UMA INTERAÇÃO CRIATIVA NECESSÁRIA
}

Isabel Lanner Carvallho Benedetto, MSc.

PUCRS

isabelcbenedetto@gmail.com

Janaina Luisa da Silva Moroni, doutoranda Universidade Federal do Rio grande do Sul janaina.moroni@ufrgs.br

Regio Pierre da Silva, Dr.

Universidade Federal do Rio grande do Sul

regio@ufrgs.br

Resumo: Atualmente, espera-se que grande parte da população viva além dos sessenta anos (OMS, 2015). A análise deste fato abre inúmeras questões sobre o tratamento que as pessoas de idade avançada necessitam e de como se relacionam com seu meio ambiente. Os projetistas devem pensar criativamente em projetos favoráveis a idosos. Neste sentido, este artigo apresenta abordagem teórica-bibliográfica sobre idosos e cidades, com exemplos de projetos estrangeiros e nacionais, de calçadas focadas no bem-estar destes indivíduos. Foi considerado o método de análise SWOT (sigla em inglês para Força, Fraqueza, Oportunidade e Ameaça), aplicadas aos projetos destinados a idosos. Os resultados apresentados focam nas normas e legislação brasileira para projetos de calçadas para melhoria de vida dos anciãos.

Palavras-chave: criatividade, idosos, cidades.

\begin{abstract}
Currently, it is expected that much of the population live beyond the age of sixty (OMS, 2015, p.3). The analysis of this fact opens several questions about the treatment that older people need and how they relate to their environment. Designers must think creatively in favorable projects for the elderly. Thus, this article presents theorical-bibliographic approach to elderly and cities, with examples of elder-focused projects of sidewalks, from abroad and locals as well. The SWOT analysis method was applied. The presented results focus on the Brazilian legislation and regulation $n$ for projects of sidewalk to improving lives of the elder people.
\end{abstract}

Keywords: creativity, elderly, city. 


\section{INTRODUÇÃO}

A população idosa é aquela a partir dos 60 anos de idade em países em desenvolvimento e nos países desenvolvidos este limite sobe para os 65 anos de idade (OMS, 2007). A expectativa mundial de vida dos idosos aumentou 20 anos desde 1950 e temse a previsão que aumente mais 20 anos até 2050. O aumento dos idosos quadruplicará nos países em desenvolvimento nos próximos 50 anos (ONU, 2002, p.27). Este é um fenômeno mundial, não visto na história da humanidade. No mundo inteiro, o número de pessoas em idade avançada deverá representar um quinto do total em 2050, segundo o IBGE (2002). A população mundial está envelhecendo (OMS,2015), a partir disso pondera-se sobre a capacidade da sociedade de adaptar-se a essa nova realidade.

A população de idosos precisa de atenção no sentido de obter meios para facilitar suas atividades cotidianas. Estes meios perpassam todo o cotidiano do idoso, desde possuir autonomia para caminhar pela cidade até decidir sobre sua rotina, em todas estas situações um projeto adequado pode ajudar a melhorar as formas de interação com o meio em que vive.

Neste artigo são abordadas as interações dos idosos com a cidade, especificamente, com as calçadas. Aparentemente restritivo, o ambiente da cidade pode, por vezes, ser hostil aos idosos. Tarefas simples, como atravessar uma rua na faixa de pedestres, subir e descer da calçada, ou mesmo andar por ela, podem se transformar em verdadeiros desafios. Neste sentido, cabe aos pesquisadores, encontrar soluções criativas para ampliar as oportunidades de convivência e usufruto da cidade e do cotidiano aos adultos em idade avançada. A OMS (2015), recomenda um enfoque social sobre o envelhecimento humano e considera como meta construir um mundo favorável aos idosos.

Pensando nisso, os autores com experiência docente em universidades públicas e privadas dos cursos de Arquitetura do Brasil, sentiram a necessidade de realizar um estudo teórico-bibliográfico com objetivo de conscientizar os estudantes, docentes e profissionais de arquitetura para realizarem projetos criativos para idosos. Os exemplos usados foram as calçadas das cidades, observando os benefícios que pode apresentar aos idosos. Portanto, o artigo foi estruturado em quatro partes: (i) o crescimento da população idosa nas cidades, (ii) explanação dos procedimentos metodológicos, (iii) apresentação das discussões e análises dos resultados obtidos e (iv) finalizando com as conclusões encontradas neste trabalho.

\section{O CRESCIMENTO DA POPULAÇAO IDOSA NAS CIDADES}

O envelhecimento da população e a urbanização são o culminar de um bemsucedido desenvolvimento humano no século passado de acordo com o Guia Global das Cidades Amigas das Pessoas Idosas (OMS, 2007). A paisagem, os edifícios, o sistema de transportes e habitação da cidade contribuem para uma mobilidade confiante, um comportamento saudável, para a participação social e a autodeterminação. Esses fatores podem tem seu lado negativo caso não haja preocupação com as consequências de uma cidade que não apresenta características amigáveis, proporcionando isolamento, inatividade ou exclusão social. Ressaltar a importância do Envelhecimento Ativo em cidades que prestam apoio e estimulam a capacitação é uma eficaz abordagem, tendo em vista a manutenção da qualidade de vida e a prosperidade num mundo cada vez mais idoso e urbano. O Envelhecimento Ativo é o processo de otimização de condições de saúde, participação e segurança, de 
modo a melhorar a qualidade de vida à medida que as pessoas envelhecem (OMS, 2007).

O relatório da OMS (2015) define o Envelhecimento Saudável como o processo de desenvolvimento e manutenção da capacidade funcional que permite o bem-estar em idade avançada. Este relatório determina quatro áreas prioritárias de ações que podem promover a melhoria das capacidades das pessoas idosas. Entre estas ações estão: desenvolver sistemas de cuidados a longo prazo, e, criar ambientes favoráveis ao idosos (grifo dos autores).

Os indivíduos de uma mesma faixa etária apresentam grande heterogeneidade de características biológicas, psíquicas e sociais. Inoye, Pedrazzani e Pavarini (2008, apud Albuquerque e Carvalho, 2013) posicionam o conceito de qualidade de vida como amplo, incluindo não apenas as condições de saúde, o controle de sintomas e as intervenções médicas, há que se incluir dimensões menos tangíveis, como o sentido de segurança, a dignidade pessoal, as oportunidades de atingir objetivos, a satisfação com a vida, a alegria, entre outros.

\section{EXPLANAÇÃO DOS PROCEDIMENTOS METODOLÓGICOS}

Realizou-se uma pesquisa teórica-bibliográfica com a observação de imagens digitais de cidades estrangeiras e uma brasileira. Este é um estudo interdisciplinar nas áreas de arquitetura, design, ergonomia e gestão estratégica na implantação de projetos criativos destinadas às calçadas para idosos. Assim, foram utilizados três instrumentos de avaliação para os passeios públicos. A técnica inicial é com moodboard, para simular com alunos, docentes, profissionais e pedestres, os projetos existentes destinados a idosos e fruição do passeio. As imagens favorecem o processo analítico de projetos realizados nas cidades italianas e holandesas, avaliando os pontos positivos e negativos. O segundo instrumento é brainstorming, que pode ser utilizada individualmente ou em grupos. O objetivo é lançar opiniões, favoráveis ou não, sobre os projetos apresentados. O terceiro e último é a matriz SWOT, que consiste em traçar horizontes quanto a forças [strengths], fraquezas [weaknesses], oportunidades [opportunities] e ameaças [threats] organizacionais (neste caso de projetos destinados para idosos).

Deste modo, a primeira etapa é abordar o tema do idoso e a relação com as cidades para conscientizar a criação de projetos favoráveis a este grupo em ascensão. A segunda etapa é mostrar imagens de projetos que foram aplicadas no exterior. $\mathrm{Na}$ terceira etapa realiza-se análise dos exemplos citados com brainstorming, apontando pontos positivos e negativos. Para organizar os dados foi usado o método SWOT, abordando questões das normas da legislação e ergonomia para idosos quanto aos espaços das calçadas e verificando o apoio dos municípios para o desenvolvimento do projeto. Contribuindo assim com reflexões e criatividade para projetos focados na cidade e o idoso para o Brasil.

\section{APRESENTAÇAO DAS DISCUSSÕES E ANÁLISES DOS RESULTADOS OBTIDOS}

De acordo com o Plano Internacional para o Envelhecimento (ONU, 2003), a criação de ambientes propícios pode fazer com que a sociedade se interesse por estreitar a solidariedade entre grupos de gerações e combater a falta de respeito e a discriminação de que são vítimas os idosos. 


\subsection{Análise das calçadas holandesas}

$\mathrm{Na}$ Holanda propõem-se calçadas contendo pictogramas, com informação de um tipo de exercício leve, para estimular atividades físicas nos idosos (Figura 1).
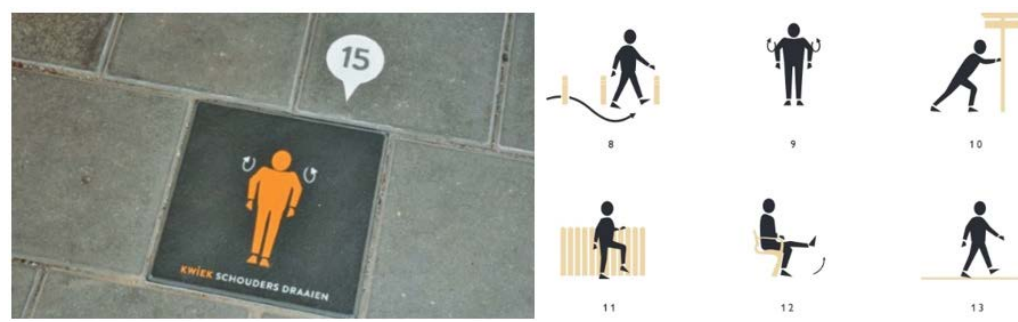

Figura 1 - Calçadas holandesa com mensagem de exercício leve para idosos.

Fonte: Elaborado pelos autores, com base na pesquisa realizada.

Utiliza-se o instrumento Brainstorming, sobre o tema "estimular atividades físicas nos idosos que não vão em academias. A seguir 13 opiniões e ideias percebidas pelos autores em suas disciplinas em sala de aula juntamente com os alunos em pesquisas com pedestres: (i) espaço da academia de ginástica para as calçadas públicas das cidades; (ii) fácil realização; (iii) custo baixo e conscientização de pausa para movimentos leves; (iv) é bonito, prático, e apoia idosos; (v) nem todos irão praticar a pausa para movimentos leves; (vi) incentiva a pausa para movimentos e assim que os idosos formarem o hábito de parar para se exercitar, mais pessoas o farão; (vii) possui variedade de exercícios leves, com diversos pictogramas mostrando o uso do mobiliário urbano (UM), presente nas calçadas; (viii) elimina obstáculos de mobilidade na calçada pois utiliza o existente; (xi) facilidade por substituir lajota de calçada por pictograma informacional de exercícios leves; $(x)$ combinar a mobilidade da calçada com a lembrança de exercícios em curto espaço de tempo, em 15 minutos; (xi) readapta calçadas com informações de exercícios práticos; (xii) adapta a legibilidade do pictograma para idosos através do contraste de cor do pictograma (no caso a cor laranja) e forma do desenho reconhecido internacionalmente; (xiii) inverter a função da calçada, não apenas de "passagem" de circulação, mas de "pausa" para conscientizar o bem-estar dos idosos. Em seguida, aplicou-se a matriz SWOT, (Quadro 2).

Quadro 2: Matriz SWOT aplicado a projeto Holandês.

\begin{tabular}{|c|c|c|c|c|}
\hline \multicolumn{5}{|c|}{ MATRIZ SWOT: Projeto Holandês } \\
\hline \multirow[t]{2}{*}{ Projetistas } & \multirow{2}{*}{ 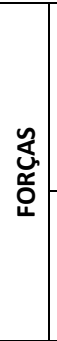 } & $\begin{array}{l}\text { Quais são os aspectos positivos? } \\
\text {-Incentiva exercícios leves - Combina } \\
\text { calçada com exercícios - inverter a função } \\
\text { da calçada: "passagem" para "pausa" para } \\
\text { conscientizar o bem-estar dos idosos. }\end{array}$ & \multirow{2}{*}{ 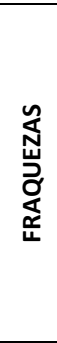 } & $\begin{array}{l}\text { Quais são os aspectos negativos? } \\
\text { Nem todos irão praticar a pausa para } \\
\text { movimentos leves. }\end{array}$ \\
\hline & & $\begin{array}{l}\text { Quais são as facilidades de criação, produção, } \\
\text { execução e implantação? Mobiliário } \\
\text { existente. Substituição fácil lajota por } \\
\text { pictograma. }\end{array}$ & & $\begin{array}{l}\text { Existe apoio financeiro do município ou de } \\
\text { empresa? Sim, o custo é baixo do projeto, } \\
\text { pois utiliza o MU existente como apoio } \\
\text { as atividades. }\end{array}$ \\
\hline \multirow[b]{2}{*}{ Município } & \multirow{2}{*}{ 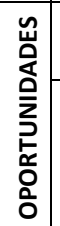 } & Existem editais de apoio a projetos? Sim & \multirow{2}{*}{ 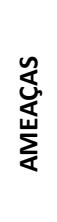 } & $\begin{array}{l}\text { Sabe-se o custo de tudo? Sim, o que foi } \\
\text { possível a sua implantação. }\end{array}$ \\
\hline & & $\begin{array}{l}\text { As leis do munícipio são favoráveis ao projeto? } \\
\text { Sim }\end{array}$ & & $\begin{array}{l}\text { A cidade está preparada para o projeto } \\
\text { (tempo, disposição, ajuste, adaptação)? Sim }\end{array}$ \\
\hline
\end{tabular}

Fonte: Elaborado pelos autores, com base na pesquisa realizada 


\subsection{Análise das calçadas italianas}

A Itália, passou por diversas tentativas de melhorias das calçadas (Figura 2, letras " $A$ ", " $B$ ", " $C$ ", " $D$ ", "G"), até chegar no tipo de calçada adequada (Figura 2, letra "F"). Hoje as calçadas primam pelo conforto para a mobilidade de idosos com custo baixo de construção e manutenção como mostra a imagem das letras "E e F" no canto inferior direito. Entretanto, em centros históricos as mudanças são difíceis em virtude da identidade e preservação patrimonial, como pode-se visualizar na imagem central superior, letra "B". Para incentivar a prática de exercícios, foi instalado um totem informativo, de um lado o mapa com os pontos turísticos da cidade. Na outra extremidade, abaixo do pictograma do homem em atividade física, um painel azul contendo a quantidade de passos dados a partir de cada ponto turístico sugerindo realizar após o percurso três exercícios de alongamento dos membros inferiores. (Figura 2, letra "G")

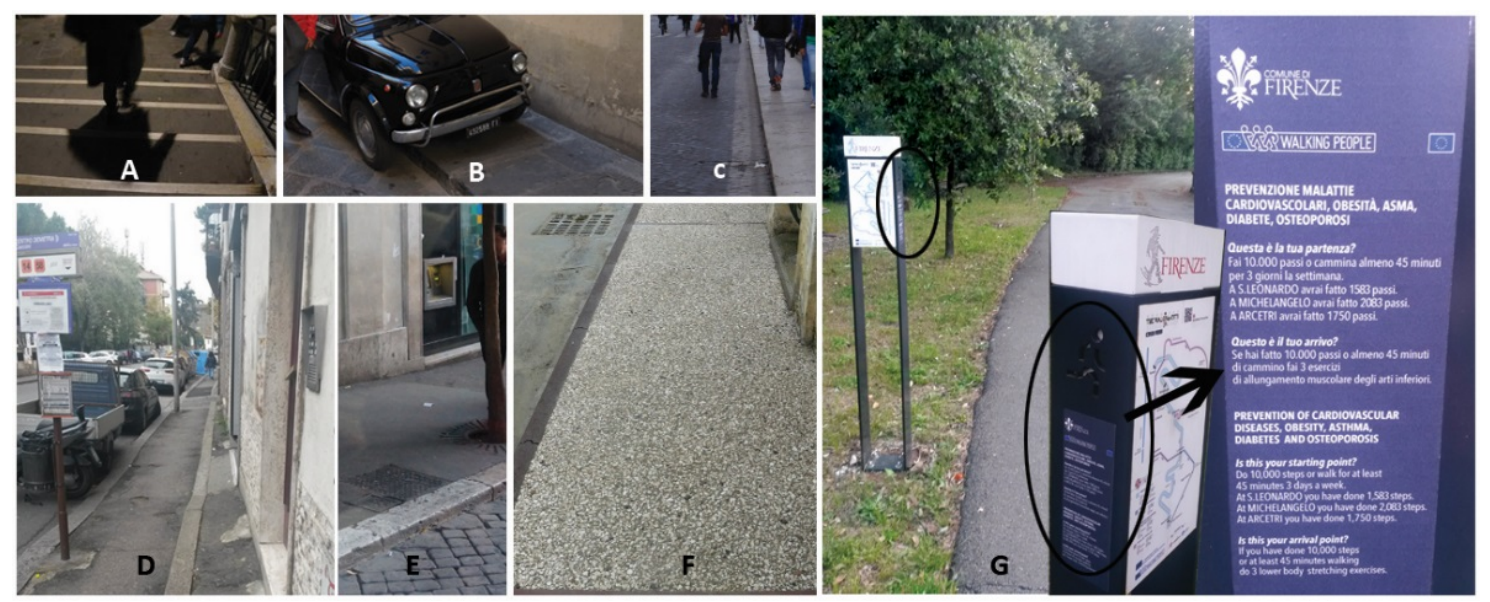

Figura 2 - Calçadas italianas de (A) Veneza, (B, D e G) Florença e (C) Roma e (E) Versão final para Itália. Fonte: Elaborado pelos autores, com base na pesquisa realizada.

Utiliza-se o instrumento Brainstorming, sobre o tema "melhorar a circulação nas calçadas com pouco investimento". Da mesma forma que a análise anterior seguem 13 opiniões e ideias percebidas pelos autores em suas disciplinas em sala de aula juntamente com os alunos em pesquisas com pedestres: (i) conforto do asfalto das ruas automotivas para as calçadas públicas da cidade; (ii) existem condições de realização; (iii) possui custo baixo, pois não precisa de mais de um funcionário para preparo e colocação de lajotas, e tampouco a compra de lajotas; (iv) confortável e bonito por não gerar o desagradável andar com buracos pelos desgastes das lajotas; (v) o aspectos negativo é confundir o limite da calçada com a rua; (vi) facilita o andar; (vii) aplicar cor diferente, ou material, no meio fio da calçada; (viii) primar pelo conforto na calçada; (xix) eliminar obstáculos e desníveis provocados por lajotas desgastadas; (x) substituir a lajota por betume; (xi) combinar calçada com rua; (xii) readaptar a construção das ruas para as calçadas; (xii) adaptar o nível da altura das calçadas para melhorar a mobilidade de idosos; (xiii) inverter a função estética com a função prática, sem uso de lajotas decorativas que possam interromper o fluxo tranquilo de andadores, cadeiras de roda, ou o andar com muletas dos idosos. Após aplicou-se a matriz SWOT (Quadro 03). 
Quadro 3: Matriz SWOT aplicado a projeto italiano.

\begin{tabular}{|c|c|c|c|c|}
\hline \multicolumn{5}{|c|}{ MATRIZ SWOT: Projeto Italiano } \\
\hline \multirow[t]{2}{*}{ Projetistas } & \multirow[t]{2}{*}{ 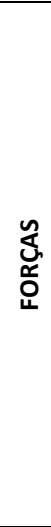 } & $\begin{array}{l}\text { Quais são os aspectos positivos? } \\
\text { - conforto no andar - cor/material diferente no } \\
\text { meio fio da calçada -adapta o nível da altura } \\
\text { das calçadas para mobilidade de idosos - } \\
\text { inverter a função estética com a função prática, } \\
\text { sem uso de lajotas decorativas que possam } \\
\text { interromper o fluxo tranquilo de andadores, } \\
\text { cadeiras de roda, etc. }\end{array}$ & \multirow{2}{*}{ 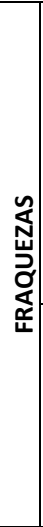 } & $\begin{array}{l}\text { Quais são os aspectos negativos? } \\
\text { - confundir o limite da calçada com a rua. } \\
\text { Nem todas as calçadas apresentam meio fio } \\
\text { de cor diferente para distinguir o que é } \\
\text { calçada do que é rua automotiva ou rua de } \\
\text { passagem de ciclista. Muitos idosos } \\
\text { reclamam de quedas pela falta de } \\
\text { identificação do meio fio. }\end{array}$ \\
\hline & & $\begin{array}{l}\text { Quais são as facilidades de criação, produção, } \\
\text { execução e implantação? } \\
\text { Eliminar a manutenção pela facilidade de } \\
\text { substituir a lajota por betume. Produção e } \\
\text { implementação rápida, já que combina com a } \\
\text { mesma produção das ruas automotivas. }\end{array}$ & & $\begin{array}{l}\text { Existe apoio do município ou de empresa? Sim, } \\
\text { pelo baixo custo de produção e } \\
\text { manutenção. }\end{array}$ \\
\hline \multirow[b]{2}{*}{ Município } & \multirow[b]{2}{*}{ 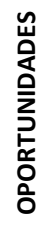 } & Existem editais de apoio a projetos? Sim. & \multirow[b]{2}{*}{ 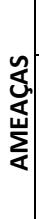 } & Sabe-se o custo de tudo? Sim \\
\hline & & $\begin{array}{l}\text { As leis do munícipio são favoráveis ao projeto? Sim, } \\
\text { mas depende da região. Regiões históricas } \\
\text { protegidas pela preservação do patrimônio } \\
\text { histórico não podem sofrer alterações nas vias. }\end{array}$ & & $\begin{array}{l}\text { A cidade está preparada para o projeto (tempo, } \\
\text { disposição, ajuste, adaptação)? Em algumas } \\
\text { regiões é difícil manter a largura da calçada, } \\
\text { especialmente em centros históricos. }\end{array}$ \\
\hline
\end{tabular}

Fonte: Elaborado pelos autores, com base na pesquisa realizada

\subsection{Análise das calçadas brasileiras}

No Brasil ainda se utiliza calçadas com lajotas e, ainda, com uso inapropriado contribuindo para o seu desgaste e insegurança de mobilidade (Figura 3). No entanto, existem legislação que configura medidas de largura e altura para promover o fácil acesso a diferentes tipos de usuários. As prefeituras buscam melhorias conforme consta em material de divulgação da cidade elaborado pela Secretaria Municipal de Obras e Viação (SMOV) de Porto Alegre, com o título "Minha Calçada: Eu curto, Eu cuido": um guia para calçada legal e acessível.
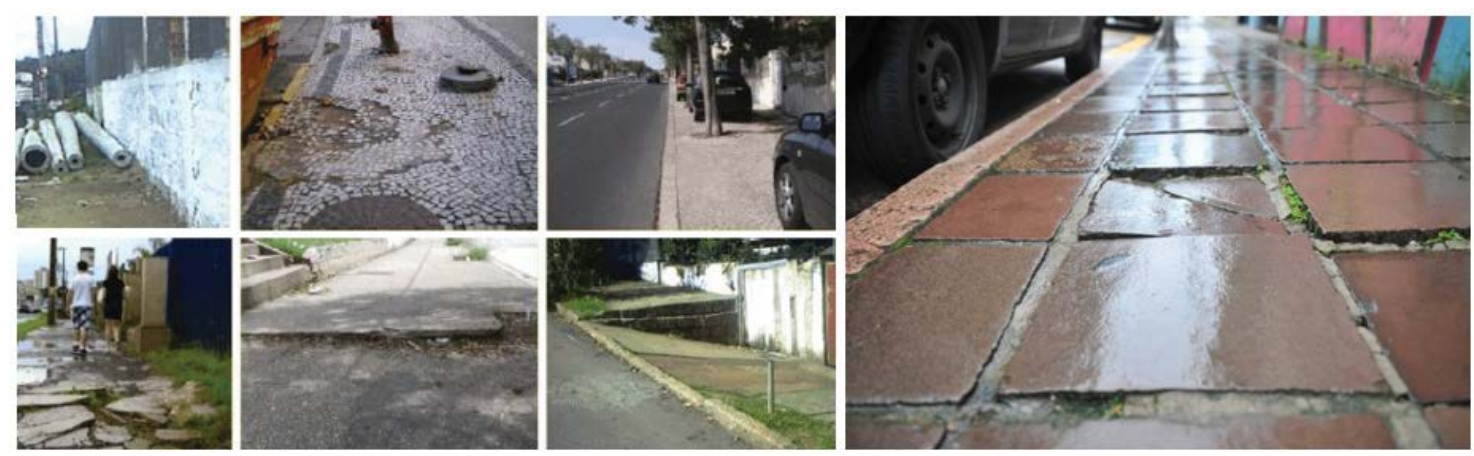

Figura 3 - Calçadas brasileiras.

Fonte: Elaborado pelos autores, com base na pesquisa realizada.

Utilizando o instrumento Brainstorming, sobre o tema "melhorar a circulação nas calçadas com pouco investimento" baseando nos resultados dos exemplos propostos na Holanda e na Itália em comparação com a situação brasileira. A seguir 13 opiniões e ideias percebidas pelos autores em suas disciplinas em sala de aula juntamente com os alunos em pesquisas com pedestres: (i) conforto e satisfação estética e de mobilidade no asfalto ; (ii) existem condições de realização; (iii) possui 
custo relativo, pois depende se será a colocação de uma calçada com ou sem pictogramas; (iv) confortável e bonito por não gerar o desagradável andar com buracos pelos desgastes das lajotas; ( $v$ ) o aspectos negativo é confundir o limite da calçada com a rua e inserir pictogramas de incentivo a exercício em ruas de fluxo alto de pedestres; (vi) proporcionar mensagens visuais e sonoras ativos com o celular do pedestre ao passar por uma determinada área da calçada; (vii) aplicar som e cor material diferente no meio fio da calçada; (viii) primar pelo conforto na calçada com rampas, e MU adequado ao bem estar dos idosos; (xix) eliminar obstáculos e desníveis provocados por lajotas desgastadas; $(x)$ substituir a lajota por concreto armado; (xi) combinar calçada com rua sem esquecer das diferenciação visual para evitar atropelamento; (xii) readaptar a construção das ruas para funcionalidade das calçadas; (xii) adaptar o nível da altura das calçadas para melhorar a mobilidade de idosos e comunicar sonoramente mudança de alturas no transcurso; (xiii) inverter o espaço público das praças para as calçadas, prolongando-as, ocupando espaços determinados para estacionamento como os projetos denominados de parklets. Primar pela função prática e oportunizar fluxo tranquilo de andadores, cadeiras de roda, ou o andar com muletas dos idosos. Após aplicou-se a matriz SWOT (Quadro 4).

Quadro 4: Matriz SWOT aplicado a projeto brasileiro.

\begin{tabular}{|c|c|c|c|c|}
\hline \multicolumn{5}{|c|}{ MATRIZ SWOT: Projeto brasileiro } \\
\hline \multirow[b]{2}{*}{ Projetistas } & \multirow{2}{*}{ 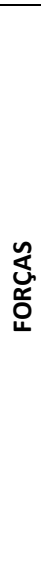 } & $\begin{array}{l}\text { Quais são os aspectos positivos? } \\
\text { Incentivo de aumento e avaliação de } \\
\text { projetos para repertório visual - } \\
\text { estudo e pesquisa para melhoria de } \\
\text { projetos para idosos. }\end{array}$ & \multirow{2}{*}{ 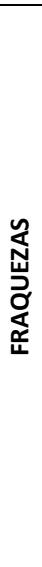 } & $\begin{array}{l}\text { Quais são os aspectos negativos? } \\
\text { Ainda é preciso aumentar a criação de } \\
\text { espaços interativos criativos para o bem- } \\
\text { estar dos idosos em qualquer bairro e cidade } \\
\text { do Brasil. Talvez pela carência de temáticas } \\
\text { de projetos de arquitetura sobre cidades e } \\
\text { idosos. }\end{array}$ \\
\hline & & $\begin{array}{l}\text { Quais são as facilidades de criação, } \\
\text { produção, execução e implantação? } \\
\text { Concreto armado, com maior duração } \\
\text { das ruas do que betume e lajota. } \\
\text { Possui maior duração e } \\
\text { consequentemente redução de } \\
\text { deformação por calor mantendo o } \\
\text { conforto de mobilidade. }\end{array}$ & & $\begin{array}{l}\text { Existe apoio do município ou de empresa? } \\
\text { Sim, como a lei que multa o proprietário cuja } \\
\text { calçada diante de seu imóvel esteja fora das } \\
\text { condições aptas para a boa mobilidade. }\end{array}$ \\
\hline \multirow[b]{2}{*}{ Município } & \multirow[b]{2}{*}{ 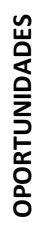 } & Existem editais de apoio a projetos? Sim. & \multirow[b]{2}{*}{ 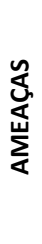 } & Sabe-se o custo de tudo? Sim \\
\hline & & $\begin{array}{l}\text { As leis do munícipio são favoráveis ao } \\
\text { projeto? Sim }\end{array}$ & & $\begin{array}{l}\text { A cidade está preparada para o projeto (tempo, } \\
\text { disposição, ajuste, adaptação)? Sim. Empresas } \\
\text { de venda de material de construção } \\
\text { conhecem e assessoram moradores para } \\
\text { renovação, manutenção de suas calçadas. }\end{array}$ \\
\hline
\end{tabular}

Fonte: Elaborado pelos autores, com base na pesquisa realizada

\subsubsection{Incentivo segundo normas de calçadas brasileiras}

A Associação Brasileira de Normas Técnicas (ABNT), atua desde 1940, é o órgão responsável pela normalização técnica no país, fornecendo a base necessária ao desenvolvimento tecnológico brasileiro.

A divisão do Mobiliário Urbano (MU) pela NBR 9283 (é de nove categorias e quatro subcategorias, porém para o estudo selecionou-se as categorias denominadas de Circulação e Transporte e também Esporte e Lazer.

No Brasil, existe o decreto 5296/04 e, a regulamentação das Leis 10.048 e 10.098 de 2000, sobre obras de acessibilidade. A ABNT editou a Norma Brasileira 
Regulamentadora (NBR) 9050/2004 que providencia as diretrizes de: Acessibilidade a edificações, mobiliário, espaços e equipamentos urbanos. O Caderno de Referência para Elaboração de Plano de Mobilidade Urbana (BRASIL,2015) informa a preocupação em projetar, planejar e manter os locais destinados ao tráfego de pessoas, sejam eles pedestres, cadeirantes, idosos, gestantes ou pessoas com deficiências: o passeio público, as faixas de travessia, calçadões, passarelas, rampas de acesso e outros elementos construídos para o seu deslocamento, maximizando as suas condições de segurança, conectividade e conforto. Qaader (1997) comenta que a efetividade no sistema de planejamento está em promover a satisfação dos cidadãos, facilitando serviços e acesso a equipamentos urbanos a diferentes necessidades de todos os grupos. Francis (2003) e Carr et al (1992), criaram categorias de espaços públicos abertos, as calçadas constam dentre essas categorias.

Outra fonte de consulta para elaboração de calçadas é o material Guia da Calçada Legal da Secretaria Municipal de Obras e Viação (SMOV, 2016), da cidade de Porto Alegre. Neste guia encontram-se as dimensões ideais para projetar e construir uma calçada, baseado na ABNT (Figura 4).

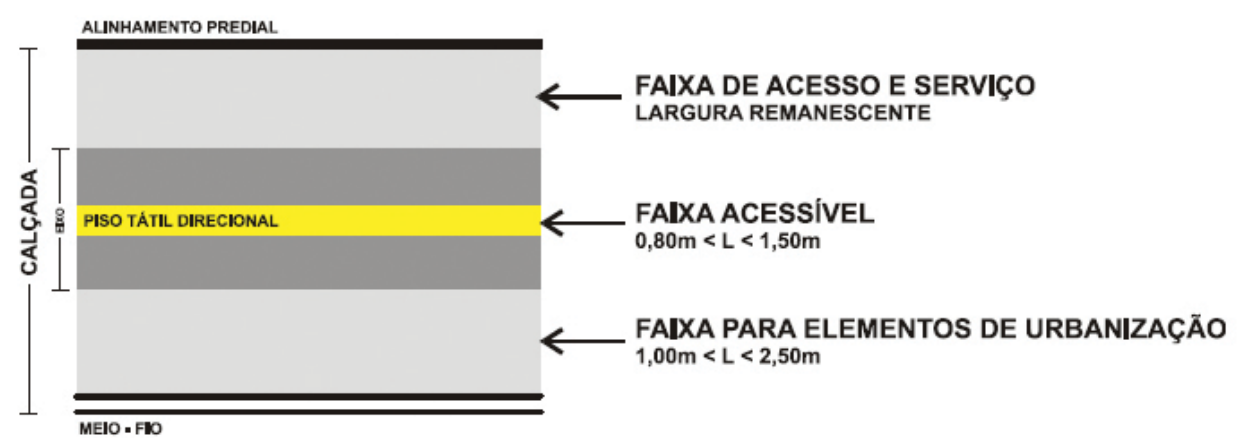

Figura 4 - Dimensões das calçadas brasileiras.

Fonte: SMOV/ABNT

Também pela ABNT 9050:2004 é possível obter informações das dimensões dos usuários, em especial dos que necessitam de acessórios de apoio para efetuar o seu deslocamento (Figura 5).
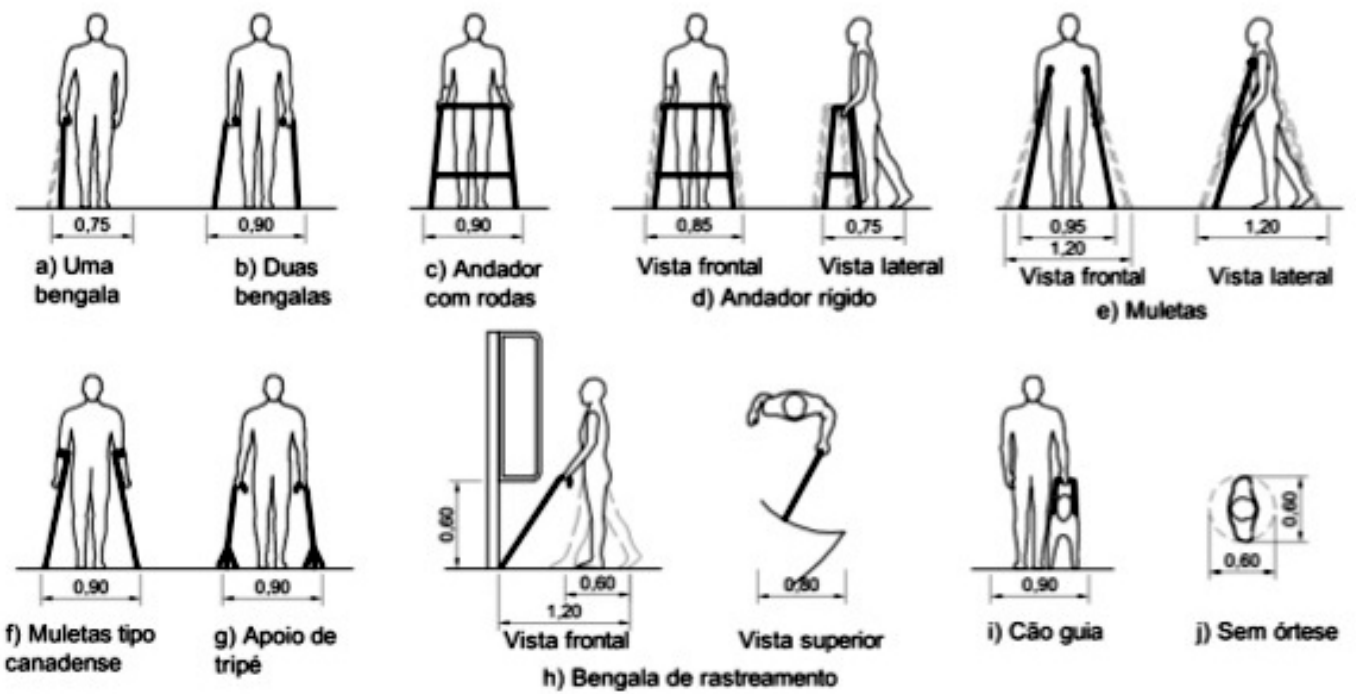

Figura 5 - Normas dimensões de usuários com bengala, andador, muleta, cão guia e sem órtese. Fonte: ABNT 9050:2004 


\subsubsection{Propostas e exemplos para calçadas brasileiras}

No Brasil, especialmente a cidade de Porto Alegre, no estado de Rio Grande do Sul, através da SMOV, apoia estudos e projetos para melhorias da mobilidade nas calçadas. Seguindo as orientações do que é possível fazer na cidade, como mostra o Guia Calçada Legal (2016) e ABNT apresentam-se algumas imagens das melhorias nas vias para a mobilidade (Figura 6).
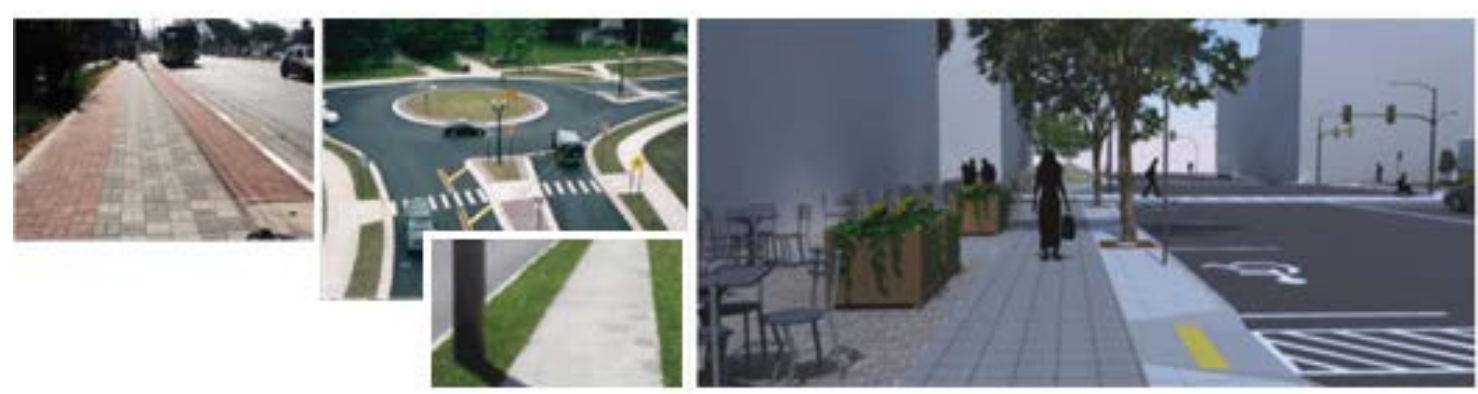

Figura 6 - Proposta de calçadas brasileiras.

Fonte: SMOV

\section{DISCUSSÕES}

Lobach (2001) já comentava que a história de um produto, neste caso as calçadas, tem a finalidade de extrair dados para o novo desenvolvimento. Bonsiepe (1984) utilizou as técnicas de analise diacrônica e sincrônica para avaliar os pontos positivos dos produtos existentes para facilitar o desenvolvimento de novos produtos com maiores satisfações. Sincronia é a análise dos produtos de uma mesma época. Diacronia é a análise dos produtos seguindo lógica cronológica sequencial de tempo. Neste estudo optou-se pela técnica de analise sincrônica.

Observando as matrizes de análise percebe-se que nem sempre os agentes públicos necessitam dispender grandes recursos para modificar de forma amigável uma calçada. Nos exemplos da Holanda, Itália e Brasil percebe-se que existem normas padronizadas e internacionais para promover o bem-estar dos habitantes no usufruto dos espaços públicos. A questão está no uso da criatividade para atender as características dos diferentes espaços e públicos de uma cidade.

De uma maneira simples, rápida e inteligente, pode-se requalificar a espaço urbano, de forma a obter-se a valorização e proteção do pedestre. A nova visibilidade que se pode dar a este espaço, não apenas como um local de passeio, mas também como um ambiente para estar, enriquece o espaço público.

Nos seus estudos Lynch (1997) enfatiza a importância de espaços nas cidades contendo legibilidade, orientabilidade e contribuindo para uma boa análise visual urbana. Essa legibilidade é a qualidade de visual da cidade lida através da imagem mental dos seus habitantes. A orientação é o que o indivíduo memoriza pelos elementos de uma cidade para o seu deslocamento, por exemplo uma calçada bem planejada e contendo cores, ou até mesmo desenhos de incentivo à prática de exercícios leves são um modo de lembrar desse espaço e tomá-lo como referência de condução. Os elementos físicos que compõem a forma visual da cidade podem ser uma rua. As vias concentram espacialmente os elementos ao longo de suas margens como hábito de atividades, tipo de pavimentação ou fachadas e distribuição da vegetação. Por isso, as calçadas são os elementos urbanos mais importantes. 
Também é importante destacar que os elementos que compõem a calçada podem ser memoráveis, tais como: cor e material do meio fio, identificações para acessos a edifícios e casas, sinalização de atenção para desnível em rampa ou atravessamento de rua, com mensagem de alerta para cegos e idosos. Tudo com clareza visual e sonora. Da Silva (2008), Moroni (2008) enfatizam a qualidade urbana através de Mobiliário Urbano (MU) unindo arquitetura, engenharia e design. Segundo Serra (1997) é importante valer-se de alguns princípios básicos: funcionalidade, racionalidade e emotividade, ou seja, comunicar boas sensações ao indivíduo.

Segundo estudos recentes, apresentados no Guia Calçada Legal da SMOV de 2016, mostram as diretrizes que definem política pública nacional de mobilidade urbana em vigor e apesar de não estarem incoerentes com o conhecimento científico acumulado até o momento sobre o caminhar, não são suficientes para a garantia do bem-estar da população, como dita a Constituição Federal (BRASIL 2015).

Cabe ressaltar que a cidade deveria, com seus espaços, natural e construído, promover o convívio e a solidariedade entre as gerações de capacidades distintas. Ser o resultado da abordagem integrada e centrada na forma como as pessoas vivem.

Os pontos levantados pelos idosos ouvidos pela OMS (2007), elucidam a necessidade de melhorias em diversas situações. Foram referidas melhorias no ambiente construído desde a importância dos espaços verdes; a existência de locais com bancos para descanso; escadas não muito altas nem muito íngremes; calçadas com superfície lisa e antiderrapante; circulação com largura para a de cadeira de rodas; passeios rebaixados ao nível da rodovia; poucos obstáculos nas vias de pedestres (como automóveis estacionados, vendedores de rua); prioridade de acesso aos pedestres, em detrimento de bicicletas, skates, etc.; até semáforos de pedestres com tempos maiores e temporizadores visuais que permitam perceber quando o sinal abrirá (OMS, 2007).

Algumas destas medidas são simples e poderiam ser adotadas sem dificuldades. Para enfrentar este problema é fundamental que se sensibilize os órgãos normativos e governamentais a fim de que voltem seu olhar a este público em franco crescimento. Da mesma forma as universidades precisam visualizar este problema repassando os ensinamentos de projeto e construção aos discentes, ampliando a rede de colaboração.

\section{CONSIDERAÇÕES FINAIS}

É fundamental que se repense sobre a vida em sociedade, uma vez que o caminho natural do ser humano é o envelhecimento. É preciso construir uma sociedade mais amigável ao idoso, nos diversos setores da vida: do MU aos objetos de uso diário, no sentido de facilitar as atividades diárias.

Gehl (1987) já argumentava sobre a necessidade de vida entre os edifícios, de se promover a função prática e satisfazer os habitantes que circulam pelos espaços públicos, como no caso das calçadas. Lynch (1985) e Lang (1994) já diziam que os espaços públicos são palco para realização de diversas atividades: circulação, comércio, passeio, recreação, contato com a natureza, socialização ou simplesmente observação da vida que neles acontece. Whitaker (1971) afirma que os motivos para o crescimento de espaços públicos são os aumentos da longevidade, mobilidade e lazer. Segundo Anderson (1978), Lynch (1997) e Jacobs (1993), as ruas são situações potenciais de atividades e significados, sendo parte integral do movimento das pessoas 
e redes de comunicação. Portanto, além de uma calçada favorecedora de uma boa mobilidade também poderá ser uma referência de localização e orientação suscitando emoções de satisfação plena.

Além disso, projetos destinados a melhoria de vida dos idosos produz uma imagem positiva da cidade. O usuário idoso poderá usufruir um espaço e se sentir parte da cidade, realizando suas atividades com tranquilidade e sem medo de sofrer consequências de queda, além de não haver esforço excessivo na atenção em desviar de buracos ou de MU mal posicionados.

O mundo está cada vez mais urbano e mais idoso (OMS,2007). As cidades devem preparar-se para receber os idosos, um público que aumenta sua participação na sociedade, incentivando um comportamento saudável, auxiliando a participação social desta parcela da população. Olhar para os espaços públicos de modo a tornar mais acessível as áreas destinadas às pessoas e à mobilidade urbana, em detrimento do espaço destinado aos automóveis, pode tornar uma cidade mais amigável. Segundo Argimon (2002) o ser humano é um agente ativo do seu próprio desenvolvimento. "O desenho da cidade é como uma arte temporal, onde o ritmo é percebido de maneira individual pelas pessoas como um cenário que muda a cada instante, abrindo possibilidade para ser explorado" (LYNCH, 1997).

\section{AGRADECIMENTO}

O presente trabalho foi realizado com apoio de pesquisa internacional da CAPES, Coordenação de Aperfeiçoamento de Pessoal de Nível Superior - Brasil e da UFRGS, Universidade Federal do Rio Grande do Sul.

\section{REFERÊNCIAS}

ABNT - Associação Brasileira de Normas Técnicas. NBR 9050, Rio de Janeiro: ABNT, 2004. Acessibilidade a edificações, mobiliário, espaços e equipamentos urbanos.

ABNT - Associação Brasileira de Normas Técnicas. NBR 9283, Rio de Janeiro: ABNT, 1986.Classificação do Mobiliário Urbano - MU.

ANDERSON, S. On Streets. London: Mit Press, 1978.

AlBuquerque, M. A. L.; CARVALHO, V. C.P. Análise do Bem-estar de Idosos no Centro de Convivência da Terceira Idade in A Terceira Idade: Estudos sobre

Envelhecimento. Serviço Social do Comércio. São Paulo: SESC-GETI, v.24,n.o 56, 2013.

ARGIMON, I. I. L. Desenvolvimento Cognitivo na Terceira Idade. 2002. 134 f. Tese doutorado, Pontifícia Universidade Católica do Rio Grande do Sul, Curso de Pósgraduação em Psicologia.

BONSIEPE, Gui et al. Metodologia experimental: desenho industrial. Brasília: CNPq/Coordenação Editorial, 1984.

BRASIL, 2015. MINISTÉRIO DAS CIDADES. PlanMob: caderno de referência para elaboração de plano de mobilidade urbana. Brasília: Ministério das Cidades, 2015.

CARR, S; et al. Public Space. Cambridge: Cambridge University Press, 1992.

DA SILVA, N. R. R. Avaliação do Nível de Serviço de calçadas em cidade de porte médio, considerando a percepção de usuários e técnicos. 2008. 137 f. Tese mestrado, 
Universidade Federal do Rio Grande do Sul, Curso de Pós-graduação em Planejamento Urbano e Regional.

FRANCIS, M. Cases Study in land and community design. Urban Open Space:

Designning for user needs. USA: Island Press, 2003.

GEHL, J. Life between buildings: using public space. New York: Van Nostrand Reinhold, 1987.

IBGE, 2002. Instituto Brasileiro de Economia e Estatística. Perfil dos Idosos

Responsáveis pelos Domicílios no Brasil 2000. Comunicação Social do IBGE, 2010.

INOYE, K; et. al. Octogenários e cuidadores: perfil sócio demográfico e correlação da variável qualidade de vida.Texto-Contexto Enfermagem, Florianópolis, v.17, n.2, p. 350-357, abr./jun. 2008.

JACOBS, Allan B. Great Streets. London: The Mit Press, 1993.

LANG, J. Urban Design: the American experience, New York: Van Nostrand Reinhold Company, 1994.

LYNCH, K. La buena forma de la ciudad. Barcelona: G. Gilli, 1985.

LOBACH, B. Design Industrial: Bases para a configuração dos produtos industriais. São Paulo: Editora Edgard Blucher, 2000.

MORONI, J. L. S. Aplicação do design gráfico para o desenvolvimento de mobiliário urbano. 2008. 195 f. Tese mestrado, Universidade Federal do Rio Grande do Sul, Curso de Pós-graduação em Planejamento Urbano e Regional.

OMS. Organização Mundial da Saúde. Relatório Mundial de Envelhecimento e Saúde Resumo. 28 p., 2015.

OMS. Organização Mundial da Saúde. Guia Global das Cidades Amigas das Pessoas Idosas. 80 p., 2007.

ONU, 2002. Organização das Nações Unidas. Plano de ação internacional para o envelhecimento. Tradução de Arlene Santos. Brasília: Secretaria Especial dos Direitos Humanos, 49 p. (Série Institucional em Direitos Humanos; v. 1), 2003.

Qaader, M. Pluralistic Planning for Multicultural Cities. In: Journal of Planning Association - The Canadian Practice, 1997.

SERRA, J. M. Elementos urbanos - mobiliário y microarquitectura. Barcelona: Editorial Gustavo Gili, 2002.

SMOV - Secretaria Municipal de Obras e Viação de Porto Alegre. “Minha Calçada: Eu curto, Eu cuido" Guia para calçada legal e acessível, promovido pela Secretaria Especial de Acessibilidade e Inclusão Social: Prefeitura de Porto Alegre, 2016.

WHITAKER, B. Parks for people. New York: S. Ed. 1971. 